\title{
Study On Seepage Laws Of Completely Weathered Phyllite Slope Under Rainfall
}

\author{
ChaoQun Liu ${ }^{1}$, XiaoMing Huang ${ }^{2}$, Dan Liu ${ }^{3}$, LiQing Zhu ${ }^{3}$, Yang Sun $^{3}$ \\ ${ }^{1}$ Jiangxi Jiatexin Engineering Technology., co., LTD., Nanchang 330200, China \\ ${ }^{2}$ Jiangxi transportation consulting co. LTD., Nanchang 330200, China \\ ${ }^{3}$ Jiangxi provincial academy of transportation sciences
}

\begin{abstract}
According to the available geological data and monitoring data, the completely weathered phyllite slope dilates and softens under the condition of continuous rainfall, which is then prone to instability failure. The indoor artificial rainfall test was carried out through the construction of the slope model, and the soil moisture sensor, pore water pressure sensor and matric suction sensor were used to study the variation laws of moisture content, pore water pressure and infiltration line at the back edge, slope body and the foot of the slope under continuous heavy rainfall. According to the sensor data and recorded information, with the influence of heavy rainfall over a long period of time, the water content and pore water pressure increased firstly, then decreased, and finally stabilized. The infiltration line moved from the top, the surface and the foot of the slope to the slope body, and shallow slip failure occurred in the shallow layer of the slope body.
\end{abstract}

\section{INTRODUCTION}

The Tonggu-Wanzai expressway in JiangXi province runs through the Jiuling mountainous area, along which a large number of completely weathered phyllite slopes are distributed, and this area is also the storm center of JiangXi province. Completely weathered phyllite dilates and softens in case of water, which is prone to slope instability, seriously threatening the safe operation of the expressway and the safety of people's lives and properties.

Heavy rainfall is the main cause of such slope failure [1-3]. Simplified slope model was built up with site samples ${ }^{[4-6]}$ and the change rules of moisture content, matrix suction, saturation line and slope position shift were studied under continuous heavy rain by setting volumetric moisture content sensor, matrix suction sensor and pore water pressure sensor. All the results measured above provided references for further slope failure and reinforcement mechanism research.

\section{SOIL SAMPLES AND EQUIPMENT FOR SLOPE TEST}

\subsection{Configuration of Slope Soil Samples}

The soil used in the test was completely weathered phyllite soil collected from a slope of B5 tender of Tongwan expressway. The strength of this kind of rock and soil mass was low, easy to be softened in water, and it was like mud. After site sampling, the soil samples were prepared following the sequence of drying, crushing and sieving.

Before the test, moisture content of the soil samples was measured. Soil with the same moisture content was configured and poured into the model box.

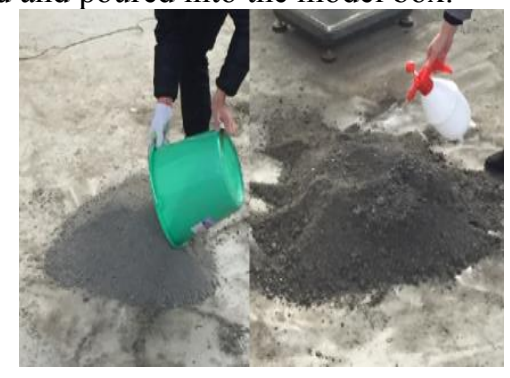

Fig. 1 Soil sample preparation

\subsection{Model Device}

The model box was made of plexiglass and steel and the size was $2 \mathrm{~m} \times 1.9 \mathrm{~m} \times 1.2 \mathrm{~m}$. To reduce the boundary effect, protective film was applied to the inner side of the plexiglass. 


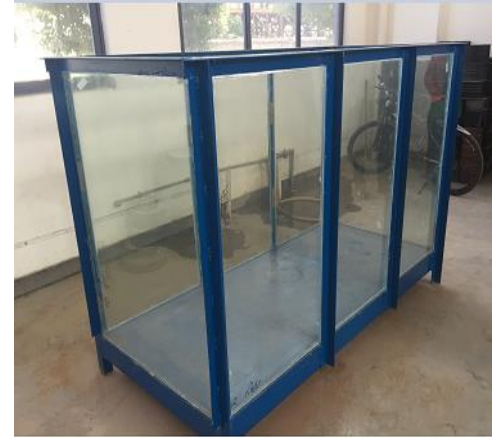

Fig. 2 Slope model box

\subsection{Artificial Rainfall Equipment}

The artificial rainfall simulation system consisted of three parts: reservoir, artificial rainfall pipeline, sprinkler head and rainfall control system. The effective rainfall area was $2 \mathrm{~m}^{2}$, the rainfall height being $4 \mathrm{~m}$ and the rainfall intensity range being $6-240 \mathrm{~mm} / \mathrm{h}$, while the rainfall uniformity coefficient was greater than 0.86 and the rainfall adjustment accuracy was $7 \mathrm{~mm} / \mathrm{h}$. The composition of rainfall system is shown in Fig 3.

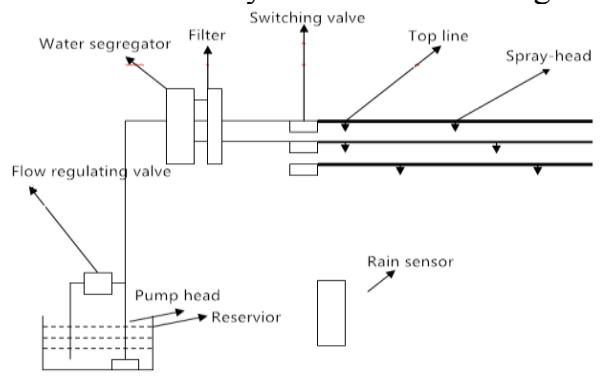

(a) diagrammatic drawing

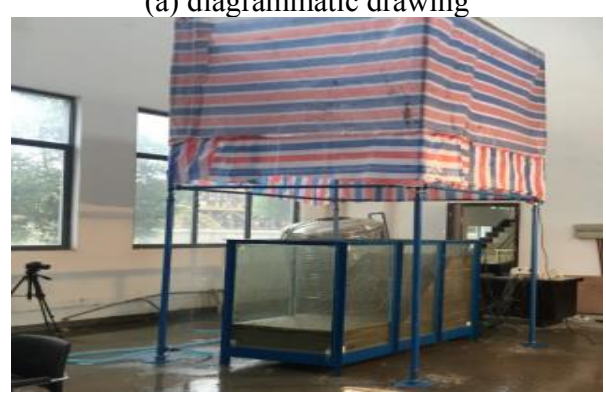

(b) entitative graph

Fig. 3 Artificial rainfall equipment framework

\section{SLOPE MODEL AND RAINFALL TEST}

\subsection{Model Construction}

In order to determine the location of soil easily and facilitate the observation of soil deformation, one layer of soil in the model box was set to be $10 \mathrm{~cm}$. The configured soil sample was poured into the model box to spread out and compacted in layers with a gradient of $1: 1$.

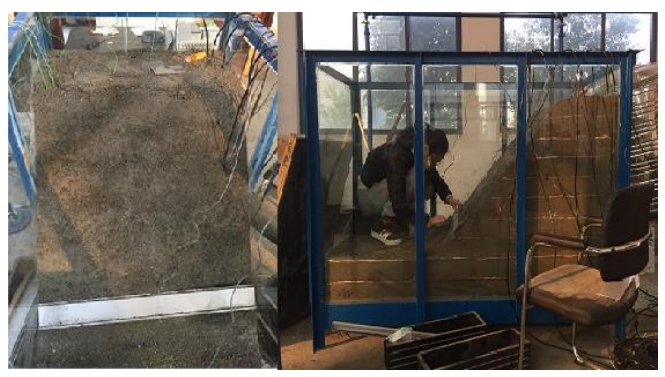

Fig. 4 Slope accumulation model

\subsection{Sensor Layout}

Seven moisture content sensors and seven matric suction sensors were placed in the slope at different depths and heights. Four pore water pressure sensors were placed at the foot of the slope and inside the slope body respectively, and the specific arrangement is shown in Fig 5.

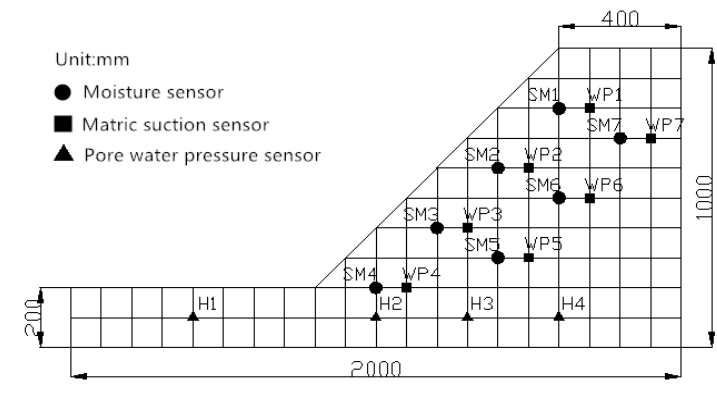

Fig 5 Slope sensor layout diagram

\subsection{Process of Rainfall Test}

Weili [7] made a statistical summary of the rainfall situation in JiangXi province since 2003. The maximum rainfall in an hour in JiangXi province ranged from 56.2 to $132.5 \mathrm{~mm}$. The rainfall intensity of this experiment was set at $70 \mathrm{~mm} / \mathrm{h}$, and the sensor was embedded and then set for 7 days. After the initial values of the sensors were stabilized, artificial rainfall began. The duration and cumulative time of rainfall are shown in Table 1.

\subsection{Date Analysis}

\subsubsection{Change law of volumetric moisture content}

With the progress of rainfall, the readings of the 7 volumetric moisture content sensors increased successively in the order of SM1, SM2, SM3, SM4, SM7, SM6 and SM5. The volumetric moisture content of SM1 and SM2 on the top of the slope increased firstly, then SM4 at the foot of the slope, and lastly SM3 on the bottom slope. As the rainfall time increased, the volumetric moisture content of SM7 on the bottom of the slope, SM6 on the middle and upper part of the slope, and SM5 on the middle and lower part of the slope increased successively. After the rainfall was stable, the volume moisture content inside the slope body was stabilized at about $34.4 \%$. The shallow sensors were 
exposed to the air due to rainfall erosion and subsequently the shallow sliding failure of the slope body, and hence their readings were smaller than those of the deep sensors, as shown in Fig 6.

Table 1 Rainfall time and cumulative duration

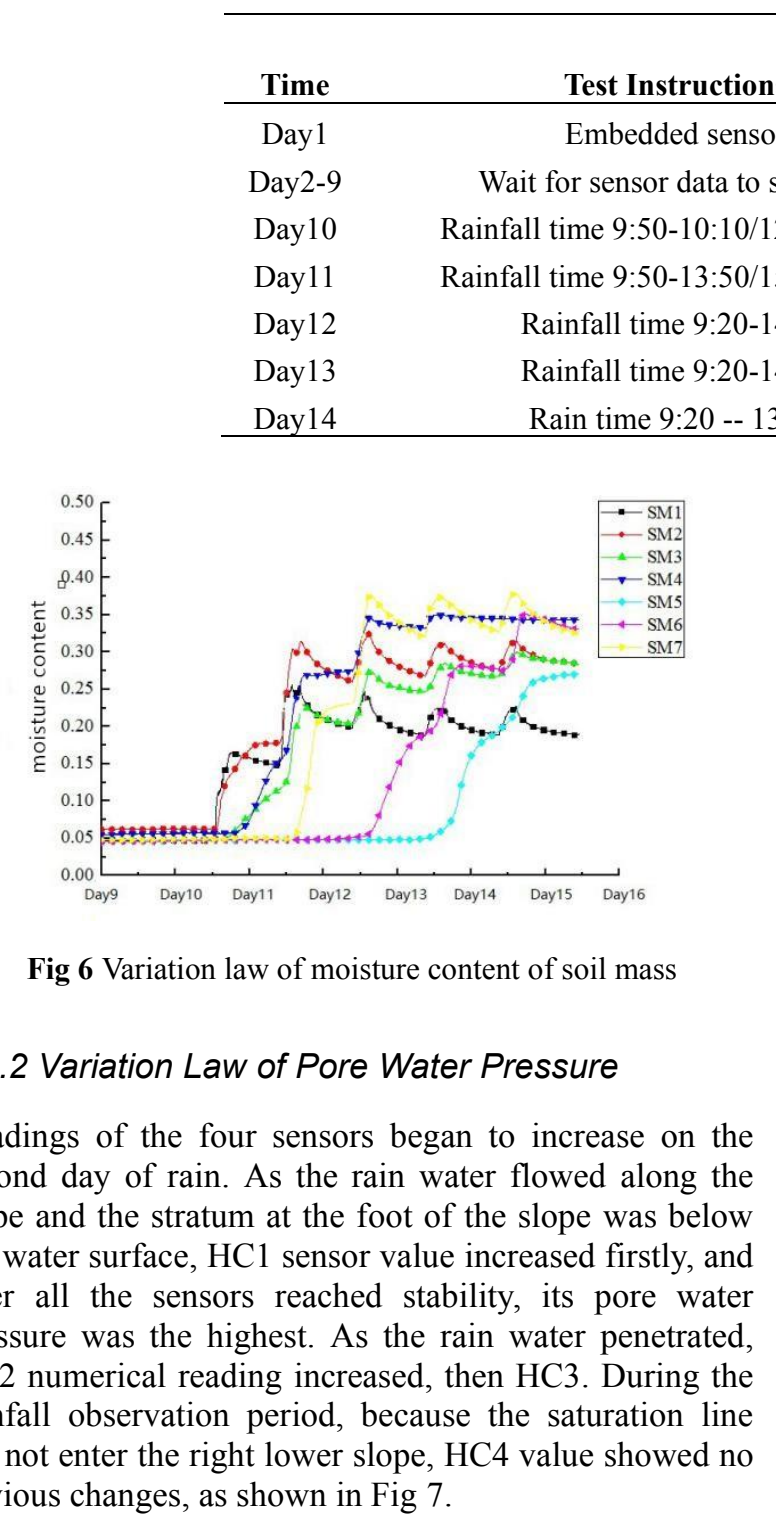

obvious changes, as shown in Fig 7.

\subsubsection{Variation Law of Matric Suction}

With the continuing rainfall, the top of the slope reached saturation state firstly, with the readings of sensor WP1, WP2 and WP7 started to reduce, then near the foot of the slope, and then in the middle of the slope. The sequence of the sensor value reduction was WP4, WP3, WP6 and WP5. The variation trend is shown in Fig 8.
Fig. 7 Variation law of pore water pressure

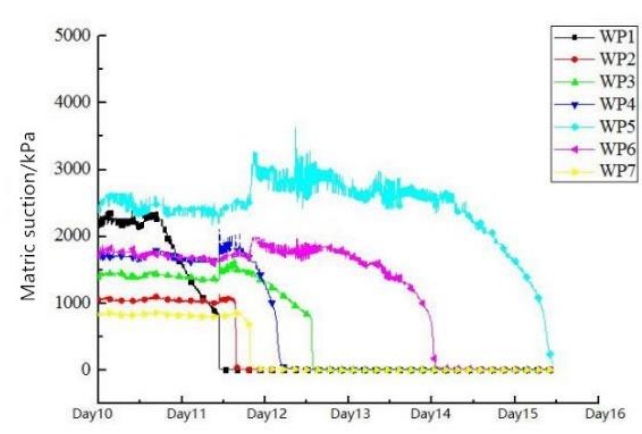

Fig 8 Variation Law Of Matric Suction

\subsubsection{Laws of Infiltration Line and Slope Deformation}

After the first two days of rainfall, infiltration area appeared parallel to the shallow surface, and small gully appeared near the top area of slope under rainfall erosion.

The invasion zone width of the bottom appeared greater than those of the slope body and the top area of the slope after the next-two-day rainfall completed. At the same time, the left ditch deepened and shallow sliding happened.

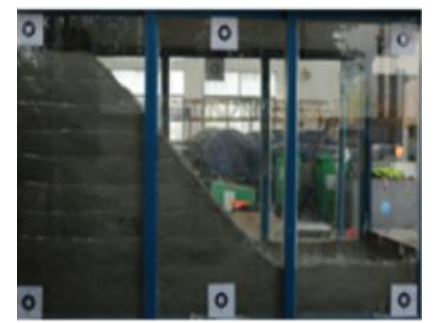

(a) before the rain

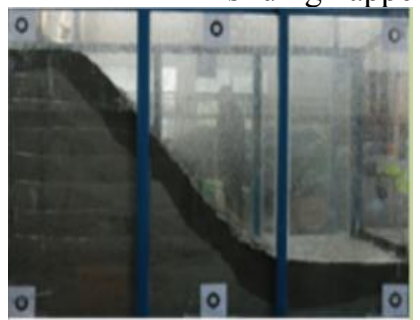

(b) the first day of rain

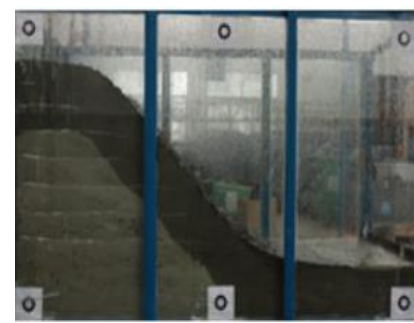

(c)the second day of rain 


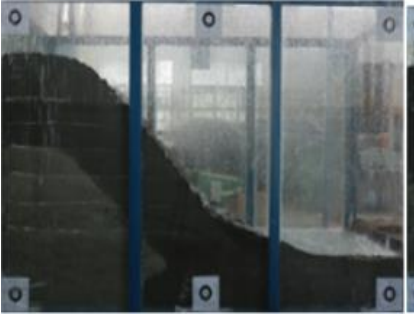

(d) the third day of rain

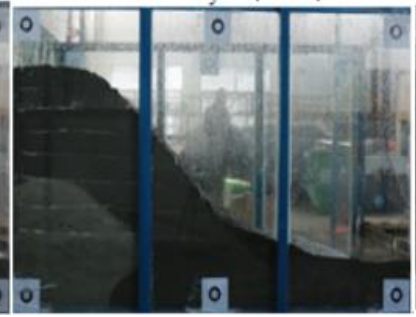

(e)the fourth day of rain

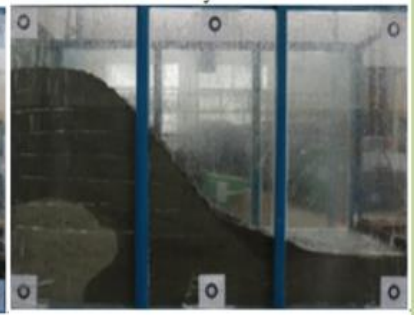

(f) the fifth day of rain

Fig 9 Variation pattern of infiltration area

The development trend of the infiltration line at different time of the whole process was summarized in Fig 10, which can clearly reflect the infiltration process of the top, slope and bottom of the slope at each stage. On the first day of rainfall, small gulfs appeared on the surface of the slope body. With continuous rainfall, the gulls on the surface of the slope body deepened and widened, and gradually developed into shallow slip failure. The slope failure is shown in Fig 11

\section{NUMERICAL ANALYSIS}

\subsection{Model Parameters}

In the analysis of this paper, the calculation formula of permeability coefficient of water in soil was cited to be defined based on the relationship between permeability coefficient and matric suction ${ }^{[8]}$ :

$$
k_{w}=a_{w} k_{w s} /\left[a_{w}+\left\{b_{w}\left(u_{a}-u_{w}\right)\right\}^{c_{w}}\right]
$$

Wherein, $a_{w}, b_{w}$ and $c_{w}$ are the permeability coefficients, $k_{w s}$ is the permeability coefficient of saturated soil; $u_{a}$ and $u_{w}$ are respectively pore gas pressure and pore water pressure; $u_{a}-u_{w}$ is the matric suction.

Relationship between saturation and matric suction:

$$
s_{r}=s_{i}+\left(s_{n}-s_{i}\right) a_{s} /\left[a_{s}+\left\{b_{s}\left(u_{a}-u_{w}\right)\right\}^{c_{s}}\right]
$$

Wherein: $s_{r}$ is the saturation; $s_{i}$ is residual saturation; $s_{n}$ is the maximum saturation; $a_{s}, b_{s}, c_{s}$ are constant parameters.

Abaqus was used for numerical simulation. The characteristic curves of hydraulic permeability coefficient and soil-water characteristic curves adopted are shown in Fig 12. The basic mechanical parameters of the slope are shown in Table 2.

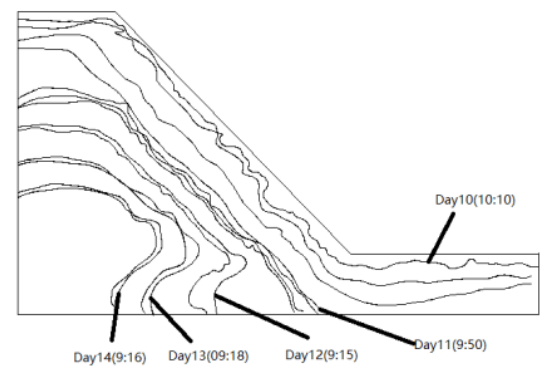

Fig 10 Variation process of infiltration line

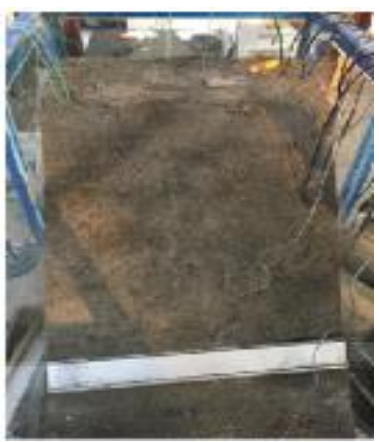

(a). before the rain

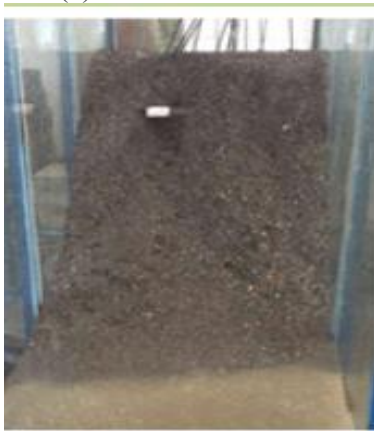

(d) the third day of rain
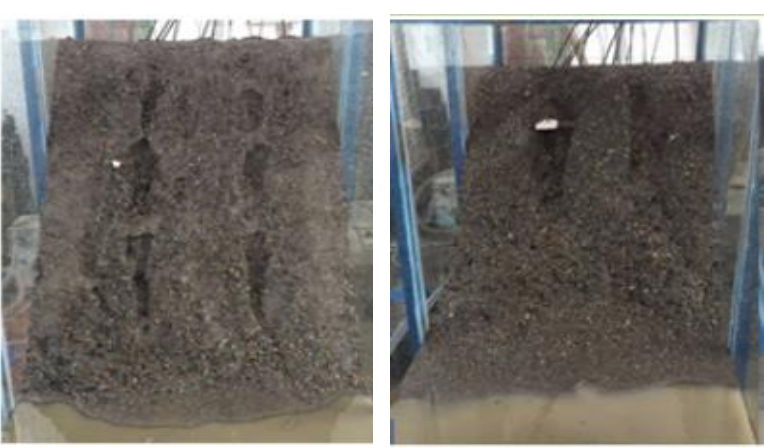

(b). the first day of rain

(c)the second day of rain

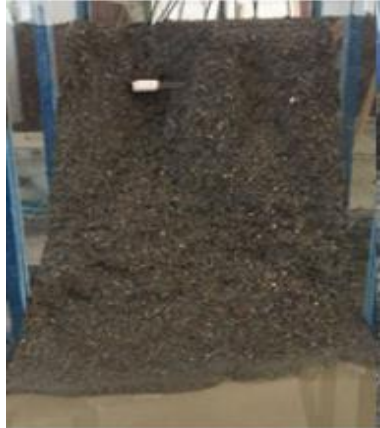

(e)the fourth day of rain

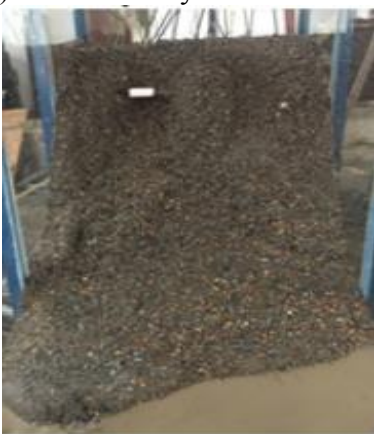

(f) the fifth day of rain

Fig. 11 Shallow failure process of slope 

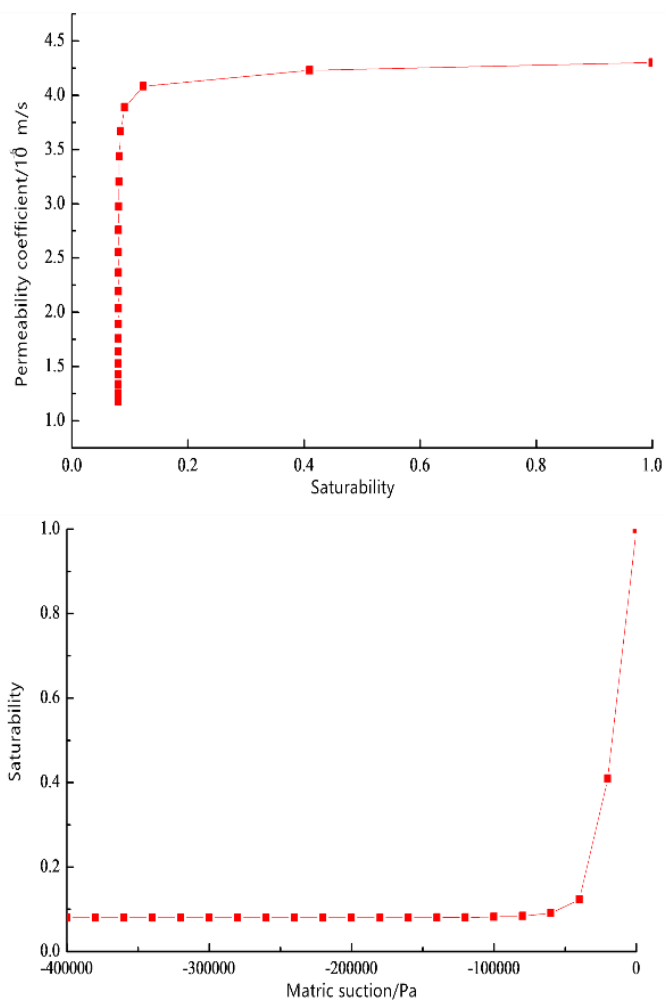

Fig 12 Hydraulic permeability coefficient characteristic curve and soil-water characteristic curve

Table 2 Parameters of the slope for calculation

\begin{tabular}{ccccccc}
\hline $\begin{array}{c}\mathrm{r} / \\
\left(\mathrm{KN} / \mathrm{m}^{3}\right)\end{array}$ & $\mathrm{E} /(\mathrm{MPa})$ & $\mu$ & e & $\mathrm{k}(\mathrm{m} / \mathrm{s})$ & $\mathrm{c} /(\mathrm{KPa})$ & $\varphi\left(^{\circ}\right)$ \\
\hline 18 & 20 & 0.3 & 0.8 & $4.3 \times 10-6$ & 25 & 18 \\
\hline
\end{tabular}

\subsection{Result Analysis}

In the process of numerical simulation, the humidity results were almost the same as in model test, while the negative pore water pressure showed a greater difference from the measured values. The main reason is that the soil water characteristic curve is calculated by empirical
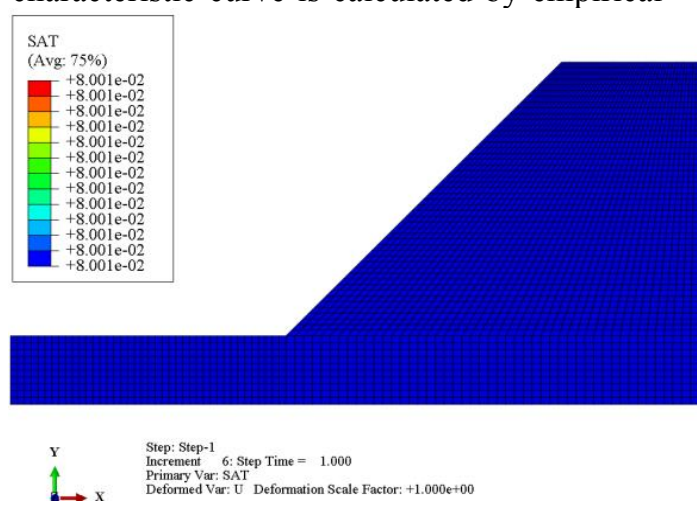

formula in the numerical simulation, rather than referring to the practical data acquired from soil samples. For different types of rock and soil, the soil water characteristic curve is quite different, which leads to the huge difference of permeability coefficient in unsaturated zone. Therefore, this paper only makes qualitative comparative analysis on the experimental and numerical simulation results.

Fig 13 showed the distribution of humidity and negative pore pressure inside the slope before rainfall. It can be seen that the distribution is completely consistent with the initial setting conditions because there is no influence of rainfall.

Fig 14 showed the distribution of saturation and pore pressure in the slope body when the slope toe reach saturation. It can be seen that the front portion of the slope toe reach saturation firstly, with positive pore water pressure which is consistent with the model test results. The main reason is that in the process of rainfall, water accumulated near the slope toe, and the isolines of saturation and pore water pressure in the body are in arc shape and don't overlap.

Fig. 15 showed the distribution of saturation and pore pressure in the slope body when the saturated zone appears at the top of the slope. It can be seen that when the foot of the slope is fully saturated, the saturated zone and positive pore water pressure begin to appear directly in the front portion of the top of the slope. With the development of rainfall, the saturated area and the negative pore water pressure area decrease gradually, and shrink to the inside in the form of arc.

Fig 16 showed the distribution of saturation and pore pressure inside the slope when 320 points in the middle of the slope reached saturation. It can be seen that the saturated regions at the top of the slope are connected with that at the foot of the slope. The unsaturated region further decreases, and the positive pore water pressure in the saturated region at the top of the slope gradually increases and is larger than that at the foot of the slope.

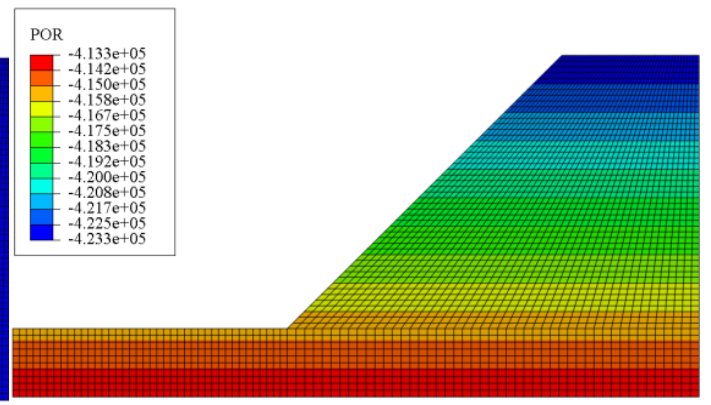

Fig 13 Saturation (left) and distribution of negative pore water pressure at the end of step 1 (right) 


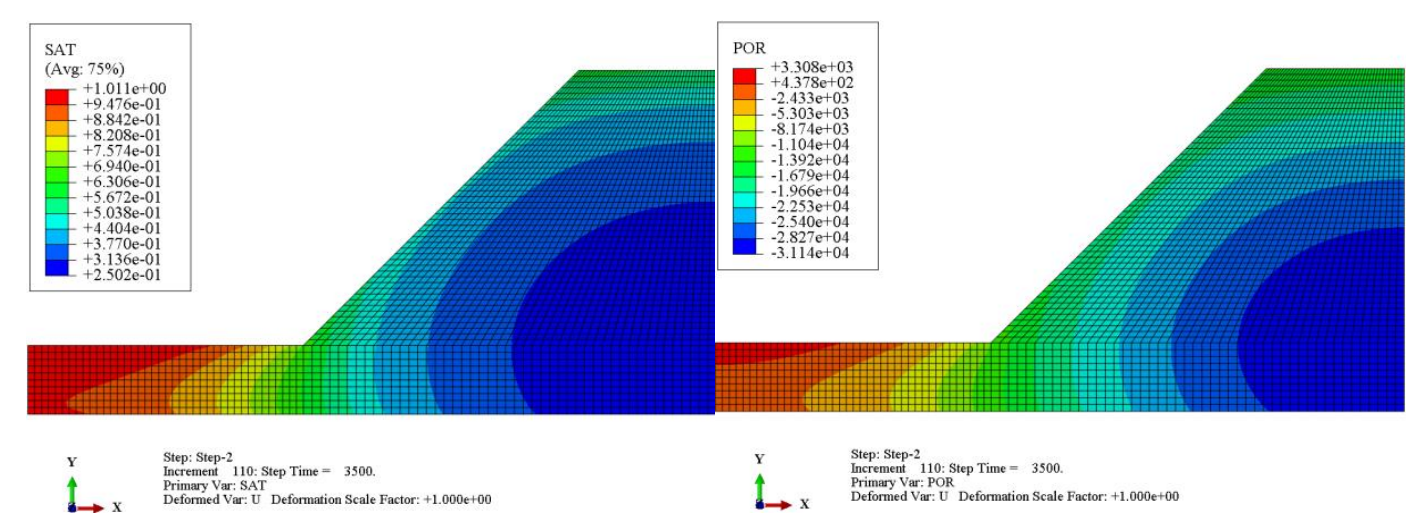

Fig. 14 Saturation (left) and pore pressure distribution (right) at foot of slope saturation
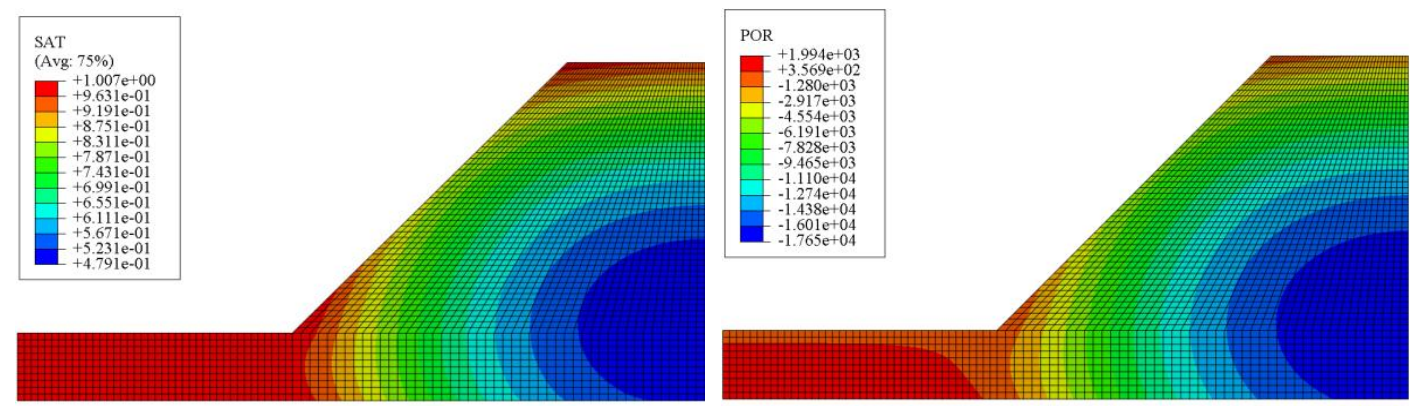

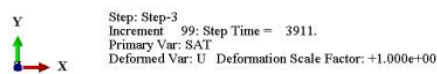

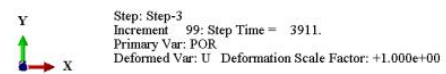

Fig. 15 Saturation (left) and pore pressure distribution (right) at peak saturation

Fig. 17 showed the calculated results when the seepage inside the slope reaches a stable state under the effect of rainfall. It can be seen from figure (a) that there is a large positive pore water pressure in the shallow layer of the slope, and since the right boundary is the drainage boundary at this time, the pore water pressure at the top of the slope dissipates. Figure (b) shows that stress concentration occurs near the foot of the slope, which is prone to plastic deformation. Figure $(\mathrm{c}, \mathrm{d})$ shows respectively horizontal displacement and vertical displacement of the slope at stable seepage state. It can
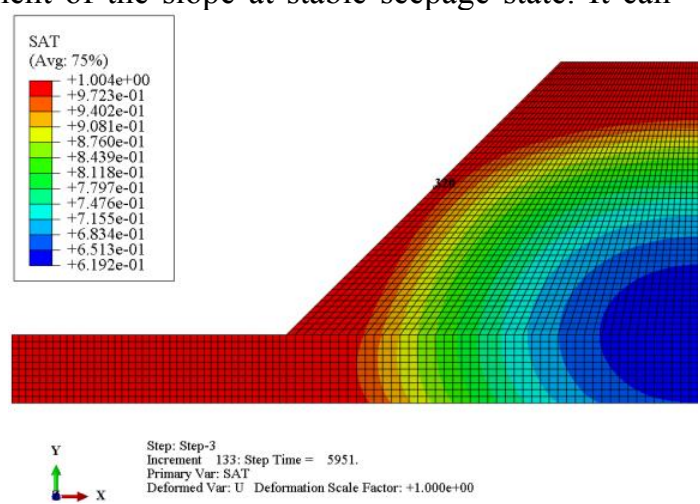

be seen that the peak horizontal displacement is less than half of the vertical displacement, and the maximum horizontal displacement occurs in the middle of the slope body, whereas the maximum vertical displacement in the front of the slope top. The displacement was produced mainly by the infiltration of rainwater which is in accordance with the model test results. With continuous rainfall, the pore pressure, Mises stress and displacement in the slope remained unchanged, and the rainwater infiltrated into the slope was discharged through the boundary on both sides.

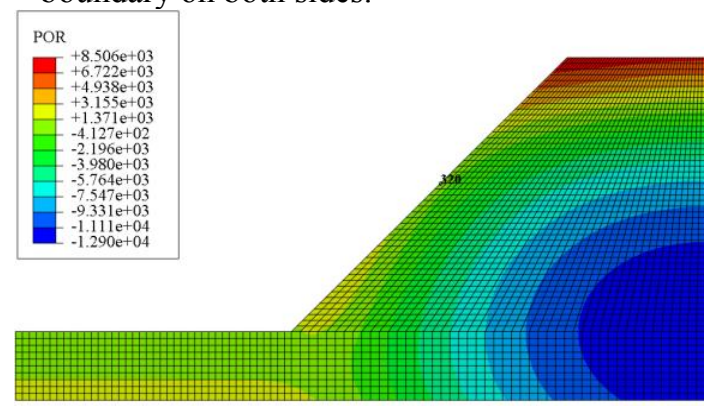

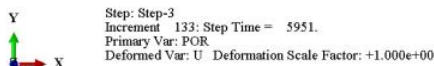

Fig 16 Saturation (left) and pore pressure distribution (right) at 320 points in the middle of the slope reaching saturation 


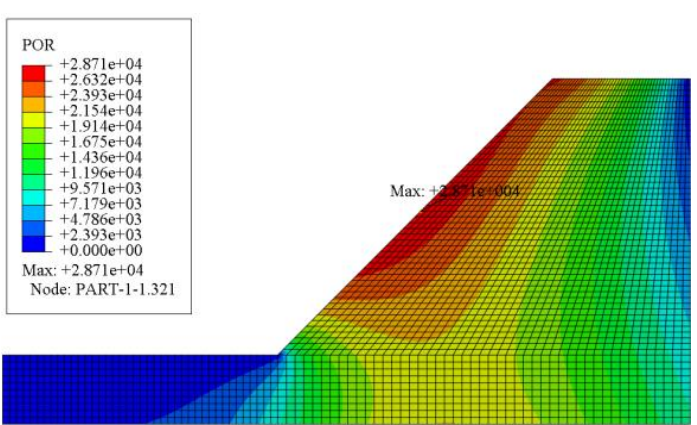

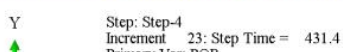

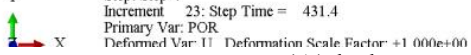

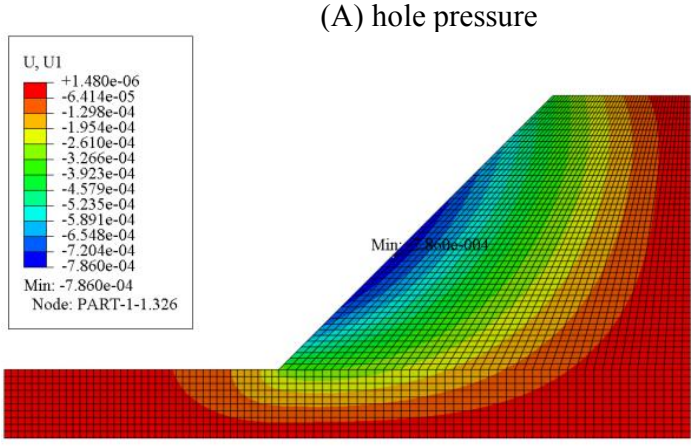

$\begin{array}{ll}\text { Y } & \text { Step: Step-4 } \\ \text { Increment } 23: \text { Step Time }= & 431.4 \\ \text { Primary Var: U. U1 } & \text { U1 }\end{array}$

(c) Horizontal displacement

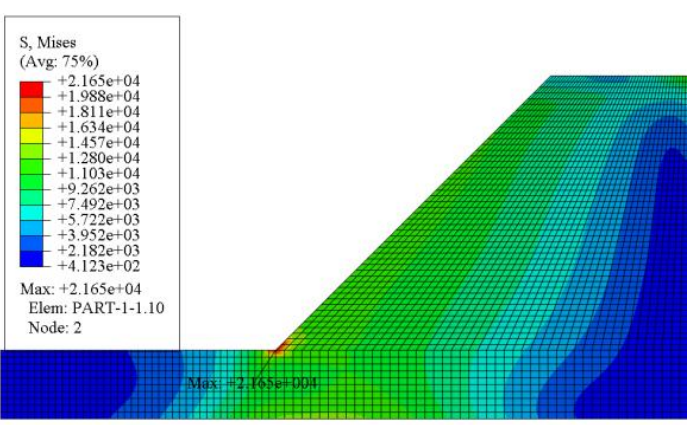

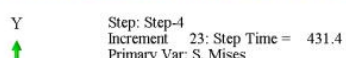

$\begin{array}{ll}\text { Increment } & \text { 23: Step Time }=431.4 \\ \text { Primary Var: S, Mises } & \text { Deformed Var: U Deformation Scale Factor: }+1.000 \mathrm{e}+00\end{array}$

(b) Mises stress

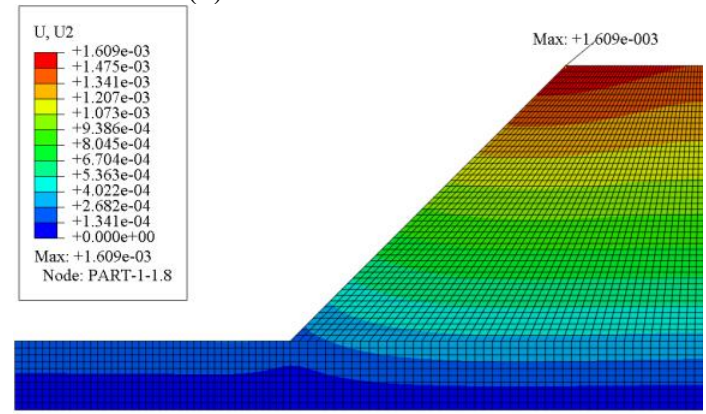

$\begin{array}{lll}\text { Y } & \text { Step: Step-4 } \\ \text { Increment } & \text { 23: Step Time }= & 431.4 \\ \text { Primary Var: U: U2 } & \text { U2 }\end{array}$

(d) Vertical displacement

Fig. 17 Calculation results of seepage stability in slope under rainfall

\section{CONCLUSION}

In this paper, the variation law of volumetric moisture content, pore water pressure, matric suction and slope deformation of the top, the surface and the foot of the completely weathered phyllite slope were studied under the condition of continuous heavy rainfall by means of artificial rainfall model test.

(1) in this test, the volume moisture contents of the top, foot and slope body increased successively, while the matric suction decreased under continuous heavy rainfall. When the saturation state was reached, the highest volumetric water content was observed below the foot of the slope and the top of the slope.

(2) the persistent heavy rains caused the pore water pressure to increase obviously under the middle of the slope and the slope toe, and the saturation line moves from the surface to the slope body. Besides, slope surface erosion and shallow sliding failure showed that the completely weathered phyllite slope was prone to shallow sliding failure under the continuous heavy rainfall. In consequence, slope surface water erosion, waterproof and drainage measures in the body should be fully considered in this kind of slope control.

(3) the numerical simulation analysis results were basically consistent with the variation laws of the parameters measured in the test. As a result, numerical analysis can be fully used to simulate the variation laws of the completely weathered phyllite slope under various rainfall conditions, so as to optimize the model test.

\section{ACKNOWLEDGEMENTS}

The financial support for this work have been provided by Youth fund project of Youth Fund Project Of Jiangxi Provincial Department Of Science And Technology, China, (Grants No. 20181BAB216028), and Jiangxi Provincial Department Of Transportation Science And Technology Project, (Grants No. 2015C0005 and 2017R0026) which are gratefully acknowledged.

\section{REFERENCES}

1. Zhou ingren, Yang tianhong, yu qinglei, et al. Influence of rainfall on the stability of thick alluvial slope [J]. Metal mine,2014(9):11-15.

2. Wu jiangpeng, Zhang guangcheng, Hou fei. Deformation and failure mechanism of soil slope under excavation and rainfall [J]. Journal of hunan university of science and technology (natural science edition),2015,30(02):73-79.

3. Qi guoqing, Huang runqiu. Study on slope displacement caused by rainfall [J]. Rock and soil mechanics,2004(3):379-382. (in Chinese)

4. Gu chunsheng, Yang weifeng. Model test of rainfall slope based on fiber optic sensing technology [J]. Metal mine,2017(02):141-144.

5. Li huanqiang, Sun hongyue, Liu yongli, et al. Application of fiber optic sensing technology in slope model test $[\mathrm{J}]$. Journal of rock mechanics and engineering,2008(08):1703-1708. (in Chinese). 
6. Luo yu, he siming, he shuichuan. Influence of rainfall types on the stability of shallow landslide [J]. Journal of geosciences of China university of geosciences, 2014,39(09):1357-1363.

7. Wei li. Research on the formation mechanism and prediction method of rainstorm-type landslide disaster [D]. Nanjing university of information technology, 2005.

8. Cho S E, Lee, s. r. Instability of unsaturated soil slopes due to infiltration [J]. Journal of Computers and Geotechnics, 2001, 28 (3) : 185-208. 